\title{
Proteolytic Cleavage and Activation of Pro-Macrophage-stimulating Protein by Resident Peritoneal Macrophage Membrane Proteases
}

\author{
Ming-Hai Wang, Alison Skeel, and Edward J. Leonard \\ Immunopathology Section, Laboratory of Immunobiology, National Cancer Institute, National Institutes of Health, and Frederick Cancer \\ Research and Development Center, Frederick, Maryland 21702
}

\begin{abstract}
Macrophage stimulating protein (MSP), which is secreted as biologically inactive pro-MSP, is activated to MSP by cleavage at a single peptide bond. Our objectives were to determine the form of MSP in circulating blood and to study proteolytic activation of pro-MSP by its target cell. Western blot of immunoaffinity-purified serum MSP showed that all the protein was pro-MSP, without detectable MSP. The circulating form of the protein is therefore pro-MSP, and conversion to MSP does not occur when blood is shed. Incubation of radiolabeled pro-MSP with murine peritoneal macrophages caused proteolytic cleavage to predominantly inactive fragments. Among several protease inhibitors, soybean trypsin inhibitor was one of two that inhibited nonspecific cleavage and revealed a macrophage activity that cleaved pro-MSP to biologically active MSP. Mouse or human serum also inhibited macrophage proteolysis of proMSP, and certain concentrations enhanced cleavage to mature MSP. Macrophage membranes had nonspecific and specific pro-MSP proteolytic activity, which was not present in macrophage culture fluids. The results suggest that control of MSP activity can occur at the level of the target cell by proteolytic cleavage of pro-MSP to mature MSP or to inactive fragments. (J. Clin. Invest. 1996. 97:720-727.) Key words: chemotaxis • kringles • inflammation • plasma • activation analysis
\end{abstract}

\section{Introduction}

Macrophage stimulating protein (MSP) ${ }^{1}$ was originally identified as a serum protein that stimulates murine peritoneal resident macrophages to make a chemotactic response to C5a (1, 2). MSP also acts directly as a chemoattractant for resident macrophages (3), alters the morphology of adherent macrophages (1), stimulates macrophage ingestion of C3bi-coated

Address correspondence to Ming-Hai Wang, Immunopathology Section, Laboratory of Immunobiology, NCI-FCRDC, Bldg. 560, Rm. 12-71, Frederick, MD 21702. Phone: 301-846-1560; FAX: 301-8466145.

Received for publication 17 April 1995 and accepted in revised form 7 November 1995.

1. Abbreviations used in this paper: AEBSF, 4-(2-aminoethyl)-benzenesulfonylfluoride; $\mathrm{CHO}$, Chinese hamster ovary; Con A, concanavalin A; I $\alpha$ TI, inter- $\alpha$-trypsin inhibitor; MSP, macrophage-stimulating protein (also called hepatocyte growth factor-like protein); STI, soybean trypsin inhibitor; uPA, urokinase-type plasminogen activator.

J. Clin. Invest.

(C) The American Society for Clinical Investigation, Inc. 0021-9738/96/02/0720/08 \$2.00

Volume 97, Number 3, February 1996, 720-727 erythrocytes (4), and inhibits expression of inducible nitric oxide synthase mRNA in endotoxin- or cytokine-stimulated macrophages (5).

We purified and partially sequenced human plasma MSP (4) and cloned an MSP cDNA from a hepatocarcinoma cell line, Hep G2 (6). Human plasma MSP is a disulfide-linked heterodimer consisting of an $\alpha$ and $\beta$ chain with molecular masses (not including N-linked carbohydrate) of 53 and $25 \mathrm{kD}$, respectively. It is a member of a family of proteins characterized by multiple copies in the $\alpha$ chain of a highly conserved triple disulfide loop structure (kringle). The family includes plasminogen (7), prothrombin (8), urokinase (9), and hepatocyte growth factor/scatter factor $(10,11)$. The gene for MSP was discovered independently (12) by screening a human genomic DNA library with a probe coding for a kringle of prothrombin. The kringle proteins are secreted as precursors, which have no biological activity until the single protein chain is cleaved into $\alpha$ and $\beta$ chains by specific serine proteases at an Arg-X bond (13), in which $X$ is most frequently Val. The $\alpha-\beta$ chain junction of MSP is also Arg-Val. The $\beta$ chain of MSP is homologous to the $\beta$ chain catalytic domain of the serine protease members of the kringle family. However, MSP and hepatocyte growth factor/scatter factor are thought to be devoid of proteolytic activity because of amino acid substitutions of the three $\beta$ chain protease active site residues, His, Asp, and Ser.

We recently showed that the human ron gene product, a trans-membrane protein tyrosine kinase (14), is a cell surface receptor for MSP (15). ron was cloned from a keratinocyte cell line library (14). Radiolabeled MSP specifically binds to Madin-Darby canine kidney epithelial cells transfected with ron cDNA (15) and to several human keratinocyte cell lines (unpublished data). Stimulation by MSP of ron cDNA-transfected cells rapidly induced phosphorylation of the RON $\beta$ chain (15). In cells expressing RON, MSP caused migration (15), shape change, or growth, depending on the cell type (unpublished data). Establishment of RON as the MSP receptor has also been independently reported (16). In view of its effects on macrophages and keratinocytes, MSP may play a role in inflammation, wound healing, and cell transformation.

One approach to understanding the biology of MSP is to identify the enzymes that can cleave pro-MSP to active MSP. Northern blotting of human tissue RNAs showed that liver is the major locus of MSP mRNA (6). We postulated that, in analogy to certain other kringle proteins, the liver secretes biologically inactive pro-MSP into the circulating blood. Inasmuch as human serum has MSP biological activity $(1,2)$, it appeared that pro-MSP was cleaved to MSP by one or more enzymes of the coagulation cascade. This idea was supported by the fact that pure serum kallikrein and Factors XIIa and XIa all cleaved pro-MSP to the biologically active $\alpha / \beta$ chain heterodimer (17).

However, we now show that, in contrast with the activities of pure coagulation enzymes, freshly shed venous blood 
does not cleave pro-MSP, and the protein in serum or EDTA plasma is pro-MSP, not MSP. In an interesting example of activating enzyme localization, we find that stimulation of macrophages in vitro by pro-MSP is due to proteolytic conversion to MSP by an enzyme on the plasma membrane of the target cell.

\section{Methods}

Reagents. Human plasma mature MSP was purified as previously described (4). Escherichia coli serotype 055:B5 LPS was from Life Technologies, Inc. (Gaithersburg, MD). Recombinant human pro-MSP and MSP were supplied by Drs. W. Yoshikawa and T. Takehara of Toyobo (Osaka, Japan). Porcine pancreatic elastase, rabbit brain cephalin, benzamidine, and concanavalin A (Con A) were from Sigma Chemical Co. (St. Louis, MO). Purified mast cell tryptase was a gift from Dr. Lawrence B. Schwartz (Medical College of Virginia, Richmond, VA). Soluble tissue factor was a gift from Dr. James Morrissey (Oklahoma Medical Research Foundation, Oklahoma City, OK). Factor VIIa was from Enzyme Research Laboratories (South Bend, IN). Mouse monoclonal anti-MSP (4), rabbit polyclonal antiMSP, and anti-MSP $\alpha$ chain (18) were as described. Cysteine-free DMEM was from Specialty Media, Inc. (Lavallette, NJ). L- $\left[{ }^{35} \mathrm{~S}\right]$ Cysteine $(>6,000 \mathrm{Ci} / \mathrm{mmol})$ was from Amersham Corp. (Arlington Heights, IL). 4-(2-aminoethyl)-benzenesulfonylfluoride (AEBSF) was from Calbiochem Corp. (Palo Alto, CA). Aprotinin, leupeptin, and soybean trypsin inhibitor (STI) were from Boehringer Mannheim Corp. (Indianapolis, IN). Protein G-Sepharose was from Pharmacia Biotech Inc. (Piscataway, NJ). Normal human serum was obtained from clotted venous whole blood by centrifugation within $90 \mathrm{~min}$ after venipuncture. $\mathrm{C} 3 \mathrm{H}$ mouse serum was obtained by tail vein bleeding.

Cells. Peritoneal resident macrophages were obtained from $\mathrm{C} 3 \mathrm{H} /$ HeN mice by lavage of the peritoneal cavity with RPMI 1640 medium (4). Con A-elicited macrophages were collected from mice that received an intraperitoneal injection of $1 \mathrm{ml}$ of Con A solution $(40 \mu \mathrm{g}$ in $0.15 \mathrm{M} \mathrm{NaCl}) 18 \mathrm{~h}$ before harvest. All cell cultures were maintained at $37^{\circ} \mathrm{C}$ in a humidified incubator containing $5 \% \mathrm{CO}_{2}$ in air.

Labeling of human pro-MSP or MSP with ${ }^{125} \mathrm{I}$. $10 \mu \mathrm{g}$ of pure recombinant human pro-MSP or plasma MSP in $30 \mu \mathrm{l}$ of $0.1 \mathrm{M}$ borate buffer, $\mathrm{pH} 8.5$, was added to $250 \mu \mathrm{Ci}$ of ${ }^{125}$ I-labeled Bolton-Hunter reagent (19) and equilibrated on ice for $60 \mathrm{~min}$. The reaction was terminated by addition of $300 \mu \mathrm{l}$ of borate buffer containing $0.5 \mathrm{M}$ glycine. After $10 \mathrm{~min}$ on ice, the reaction mixture was applied to a desalting column (Excellulose GF-5; Pierce, Rockford, IL) that had been equilibrated with PBS containing $0.25 \%$ gelatin. The iodinated protein was eluted with $1 \mathrm{ml}$ of PBS-gelatin buffer and counted in gamma counter (Gamma 5500; Beckman Instruments, Inc., Fullerton, CA). The specific activity of the labeled MSP was $\sim 400 \mathrm{Ci} / \mathrm{mmol}$.

Preparation of ${ }^{35}$ S-pro-MSP. Clone CHO-MSP18, a cell line selected for high secretion of pro-MSP, was obtained by transfection of Chinese hamster ovary (CHO) cells with MSP cDNA (6) inserted into mammalian expression vector pcDNA-3 (Invitrogen Corp., San Diego, CA). Cells were cultured in serum- and cysteine-free DMEM with $100 \mu \mathrm{Ci}\left[{ }^{35} \mathrm{~S}\right]$ cysteine for $56 \mathrm{~h}$. Concentration of pro-MSP was measured by ELISA after treatment with kallikrein (17).

Partial purification of serum pro-MSP. Monoclonal IgG anti-MSP covalently bound to Sepharose was prepared as previously described (4) and packed into minicolumns (20) to make bed volumes of $200 \mu \mathrm{l}$. A $0.5-\mathrm{ml}$ aliquot of human serum, obtained from venous blood that clotted in glass tubes at $22^{\circ} \mathrm{C}$ over a 90 -min period, was applied to an anti-MSP column; after the column was washed with PBS to remove unabsorbed protein, pro-MSP was eluted with $0.1 \mathrm{M}$ glycine buffer, $\mathrm{pH} 2.5$, containing $50 \mu \mathrm{g} / \mathrm{ml}$ cytochrome $c$. The eluate was concentrated on an ultrafilter (Centricon 10; Amicon Corp., Danvers, MA) to a volume of $\sim 50 \mu$ l.
Measurement of capacity of fresh venous blood to cleave ${ }^{125}$ I-proMSP. $10-\mu \mathrm{l}$ volumes of ${ }^{125} \mathrm{I}$-pro-MSP were added to $1.5-\mathrm{ml}$ polypropylene tubes, with or without EDTA or heparin anticoagulant. 1-ml volumes of venous blood were allowed to drip directly from the venipuncture tubing into the polypropylene tubes. After the time required for clotting, serum or plasma was collected. Proteins of 1:10 dilutions of these samples were separated by SDS-PAGE under reducing conditions on a $12 \%$ polyacrylamide gel. Labeled pro-MSP and MSP were also applied to the gel for reference markers. Radioautographs of the dried gel were made to determine the presence of ${ }^{125}$ I-pro-MSP cleavage products.

Preparation of macrophage cell membranes. Membranes were prepared by differential centrifugation of cell homogenates (21). Resident peritoneal macrophages were suspended at a concentration of

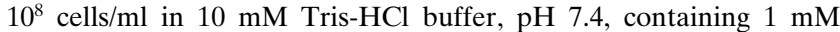
EDTA, $0.25 \mathrm{M}$ sucrose, $0.15 \mathrm{M} \mathrm{NaCl}$, and $10 \mathrm{mM} \mathrm{MgCl}_{2}$. Cells were disrupted with a tissue homogenizer (Biospec Products, Inc., Bartlesville, OK) and then centrifuged at $12,000 \mathrm{~g}$ for $20 \mathrm{~min}$ at $4^{\circ} \mathrm{C}$. Supernatants were collected and centrifuged at $41,000 \mathrm{~g}$ for $60 \mathrm{~min}$ at $4^{\circ} \mathrm{C}$. The resulting pellets were washed once with $10 \mathrm{mM}$ Na-phosphate buffer, $\mathrm{pH} 7.4$, containing $0.15 \mathrm{M} \mathrm{NaCl}, 0.5 \mathrm{mM} \mathrm{MgCl}_{2}$, and $0.15 \mathrm{mM}$ $\mathrm{CaCl}_{2}$; resuspended in buffer; and frozen at $-80^{\circ} \mathrm{C}$ until used for assay.

Cleavage of pro-MSP in vitro. $1-\mathrm{ml}$ volumes of resident or exudate peritoneal macrophages at a concentration of $1-2 \times 10^{6} \mathrm{cells} / \mathrm{ml}$ of serum-free RPMI 1640 medium were incubated in a 24-well plate for $1 \mathrm{~h}$. After washing to remove nonadherent cells, $1.5 \mathrm{pmol}$ of ${ }^{35} \mathrm{~S}$-pro-MSP was added to each well. The plate was incubated at $37^{\circ} \mathrm{C}$, culture fluids were harvested at different time intervals, and cleavage of pro-MSP was assessed as described below. For measuring the effect of serine protease inhibitors on cleavage of pro-MSP, different protease inhibitors were added to adherent macrophages $0.5 \mathrm{~h}$ before the addition of ${ }^{35} \mathrm{~S}$-pro-MSP. The capacity of macrophage cell membranes to cleave pro-MSP was assessed by mixing $20 \mu \mathrm{g}$ of membrane preparation with pro-MSP and incubating for $3 \mathrm{~h}$ at $37^{\circ} \mathrm{C}$. To determine if macrophage-secreted products cleaved pro-MSP, resident or exudate macrophages were cultured with or without $1 \mu \mathrm{g} / \mathrm{ml}$ of LPS for $24 \mathrm{~h}$. Culture fluids were then harvested and tested for their capacity to cleave ${ }^{35} \mathrm{~S}$-pro-MSP.

Immunoprecipitation and $S D S-P A G E$. Immunoprecipitation was as described (6). Culture fluids were incubated with normal rabbit IgG bound to protein $\mathrm{G}-$ Sepharose and then mixed with rabbit antiMSP IgG coupled to protein G-Sepharose. After equilibration, the Sepharose beads were washed with Tris- $\mathrm{HCl}$ buffer and suspended in sample buffer with 2-mercaptoethanol. After $5 \mathrm{~min}$ at $100^{\circ} \mathrm{C}$, proteins were separated on a $12.5 \%$ polyacrylamide gel by SDS-PAGE at 120 V. Gels were treated with Enlightning (New England Nuclear Research Products, Boston, MA), dried at $80^{\circ} \mathrm{C}$, and autoradiographed at $-80^{\circ} \mathrm{C}$ on film (XAR-5; Eastman Kodak Co., Rochester, $\mathrm{NY}$ ) with intensifying screens.

Separation of serum macrophage protease inhibitor by gel filtration. Two HPLC gel filtration columns (TSK-4000; Beckman Instruments, Inc.) were connected in series. A $0.2-\mathrm{ml}$ volume of human serum was applied to the column and eluted at a rate of $0.5 \mathrm{ml} / \mathrm{min}$; fraction volumes were $0.5 \mathrm{ml}$. Assay for protease inhibitor activity is described in the legend for Fig. 6.

Assay for macrophage shape change. The assay was performed as previously described (4). Briefly, $1 \times 10^{6} / \mathrm{ml}$ resident macrophages were incubated in $0.5 \mathrm{ml}$ of serum-free RPMI 1640 medium in 24-well tissue culture plates. Samples to be assayed for MSP activity were added. After incubation at $37^{\circ} \mathrm{C}$ for $30 \mathrm{~min}$, cells were fixed and stained with Diff-Quik (American Scientific Products, McGaw Park, IL).

Macrophage chemotaxis assay. The assay was performed using a multiwell chamber as previously described (22). Bottom wells were filled with a 1:100 dilution of LPS-activated mouse serum and then covered with a thin polycarbonate membrane with $5-\mu \mathrm{m}$ holes. Upper wells were filled with a suspension of murine resident peritoneal cells in RPMI 1640 medium together with factors to be assayed. After 
incubation for $3 \mathrm{~h}$ at $37^{\circ} \mathrm{C}$, the chamber was disassembled, and cells were wiped away from the upper surface of the membrane. After air drying and staining with Diff-Quik, cells that had migrated and remained adherent to the lower surface of the membrane were counted with an image analyzer. Samples were assayed in duplicate. Results were expressed as the percentage of input macrophages that migrated.

\section{Results}

Presence of pro-MSP in the circulation. For the reasons outlined in the Introduction, we predicted that pro-MSP is the form that exists in circulating blood and that pro-MSP is cleaved by enzymes of the coagulation cascade when blood is shed. To test this prediction, we applied three different human sera to immunoaffinity columns that bind either pro-MSP or MSP. Bound proteins were eluted and then separated under reducing conditions by SDS-PAGE. Western blot with a rabbit antibody that detects pro-MSP or MSP showed that these three sera contain pro-MSP, with little or no detectable MSP (Fig. 1). The results indicate that pro-MSP is the circulating form of this protein. Furthermore, the absence of MSP in serum shows that blood coagulation was not associated with proMSP cleavage, in contrast to the pro-MSP convertase activity of several pure coagulation cascade enzymes (17).

To confirm this, we allowed blood from a human subject to drip directly from venipuncture tubing into tubes containing ${ }^{125}$ I-pro-MSP or MSP, with or without heparin or EDTA anticoagulant. After the time required for coagulation, proteins in serum or plasma were separated under reducing conditions by SDS-PAGE. Radioautography of the dried gel showed that neither pro-MSP nor MSP was cleaved in serum or plasma (Fig. 2).

The finding that pro-MSP, not MSP, exists in serum had to be related to the fact that human serum has MSP activity when tested on resident murine peritoneal macrophages (1). The possibility that the macrophage can function as a pro-MSP

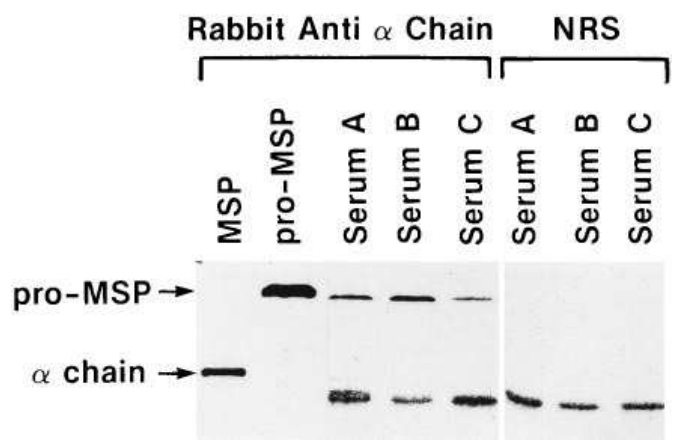

Figure 1. Detection by Western blot of pro-MSP in human serum. Three different human sera were applied to immunoaffinity columns that bind pro-MSP or MSP. Proteins in glycine eluates from the columns were separated under reducing conditions by SDS-PAGE.

Transferred proteins were probed with rabbit antibody to the $\alpha$ chain of MSP, which detects either MSP or pro-MSP. Pure MSP and proMSP standards were run in the first two lanes. The first lane shows the MSP $\alpha$ chain, which had been freed by the reducing conditions from its disulfide linkage to the $\beta$ chain. The second lane shows proMSP, which migrates as a single $\alpha / \beta$ chain, since it has not been processed by cleavage at the $\alpha / \beta$ chain junction to the disulfide-linked $\alpha / \beta$ chain heterodimer. The three serum lanes all show a pro-MSP band, without a detectable MSP $\alpha$ chain. All sera have an additional band, generated by both immune and preimmune serum (NRS).

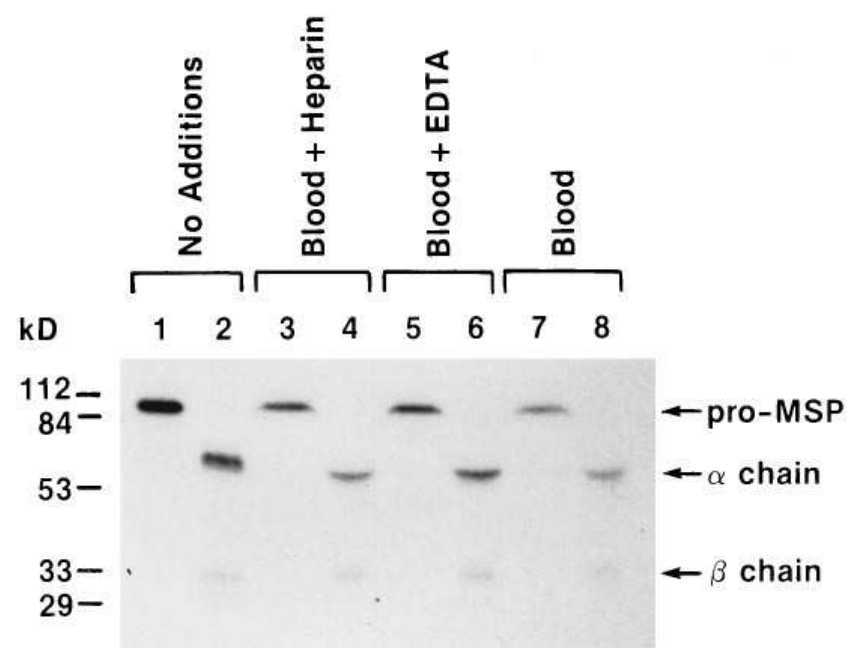

Figure 2. Radioautographs showing that fresh venous blood does not cleave pro-MSP or MSP. Lanes 1, 3, 5, and 7, pro-MSP. Lanes 2, 4, 6, and 8 , MSP. See text for description. The absence of $\alpha$ chain bands in the pro-MSP lanes shows that pro-MSP was not cleaved to the MSP disulfide-linked $\alpha / \beta$ chain heterodimer.

convertase under certain conditions was explored in the experiments described below.

Cleavage of pro-MSP by incubation with mouse peritoneal macrophages. To test whether macrophages are capable of cleaving pro-MSP, ${ }^{35} \mathrm{~S}$-pro-MSP was incubated with mouse resident peritoneal macrophages. Fig. 3 shows that pro-MSP was cleaved by macrophages in a time-dependent manner. The major bands, representing proteins with molecular masses of 47 and $35 \mathrm{kD}$, are nonspecific digestion products of pro-MSP. Specific cleavage of pro-MSP to the $\alpha / \beta$ chain heterodimer also occurred, as shown by the $\alpha$ and $\beta$ chain bands. It thus appeared that resident macrophages could cleave pro-MSP at a minimum of two loci, the predominant activity giving rise to the $47-$ and $35-\mathrm{kD}$ products. In some experiments, resident macrophages cleaved pro-MSP within $3 \mathrm{~h}$ to the point where no radioactive band at the $47-\mathrm{kD}$ position was detected (compare Fig. 5). In contrast, pro-MSP was not cleaved by incubation with human blood monocytes (data not shown). Among various other types of leukocytes, pro-MSP cleavage activity was either absent or minimal. Human blood mononuclear cells, comprising monocytes and lymphocytes, did not cleave pro-MSP. When pro-MSP was added to human blood mononuclear cells that had been incubated with endotoxin for $24 \mathrm{~h}$, minimal cleavage was observed. Murine splenic lymphocytes (nonadherent cell fraction) did not cleave pro-MSP, and did not after $24 \mathrm{~h}$ of incubation with various stimuli (LPS, TPA, MSP, IL-1, IL-2, IL-4, IL-6, IL-10, TNF- $\alpha$, TGF- $\beta$, IFN- $\gamma$ ). A murine cell line (ANA-1) with many macrophage characteristics did not cleave pro-MSP. Both resident and exudate peritoneal macrophages cleaved pro-MSP in a similar pattern. An experiment to determine if various stimuli increased resident macrophage cleavage activity showed no enhanced cleavage. Human blood neutrophils purified by dextran sedimentation did not cleave pro-MSP (four experiments). The data for this series of negative experiments are not shown. In summary, among blood leukocytes, spleen cells, and peritoneal cells, major proteolytic cleavage of pro-MSP is confined to resident and exudate peritoneal macrophages. 


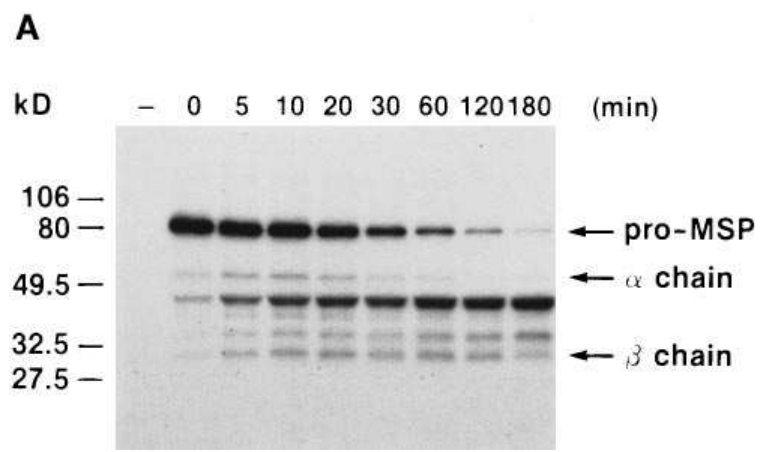

B

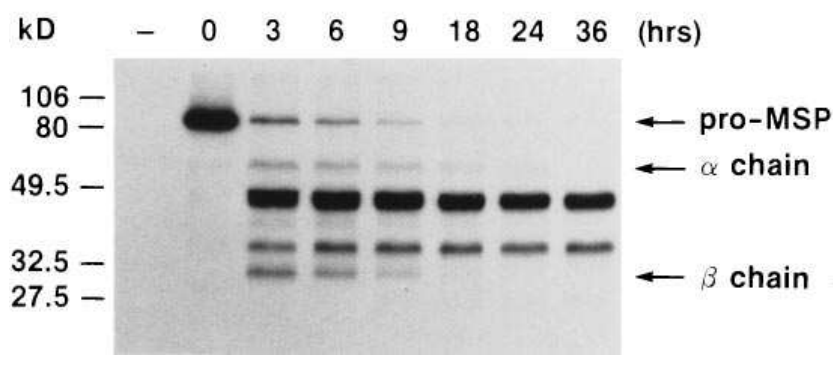

Figure 3. Cleavage of pro-MSP by incubation with macrophages. Mouse resident peritoneal macrophages at a concentration of $10 \% / \mathrm{ml}$ in serum-free DMEM were added in 1-ml volumes to tissue culture wells. After $45 \mathrm{~min}$ at $37^{\circ} \mathrm{C}$, cells were washed, and $1.5 \mathrm{nM}^{35} \mathrm{~S}$-labeled pro-MSP was added. After culture fluids were collected at the indicated times ( $A$, 0-180 min; $B, 3-36 \mathrm{~h}$ ), proteins were immunoprecipitated with IgG anti-MSP, separated by SDS-PAGE under reducing conditions, and radioautographed. Normal rabbit IgG was used as control (first lane).

Effects of serine protease inhibitors on cleavage of pro$M S P$. We tested a panel of protease inhibitors for their effects on macrophage-dependent cleavage of pro-MSP. Several members of this panel (Fig. 4, lanes 4, 5, 6, and 8) had no effect on cleavage of pro-MSP by macrophages; the major protein band was the $47-\mathrm{kD}$ nonspecific cleavage product, comparable to lane 9 (no inhibitor). In contrast, when AEBSF or STI was included in the culture of MSP and peritoneal macrophages, nonspecific cleavage was inhibited, and the predominant band

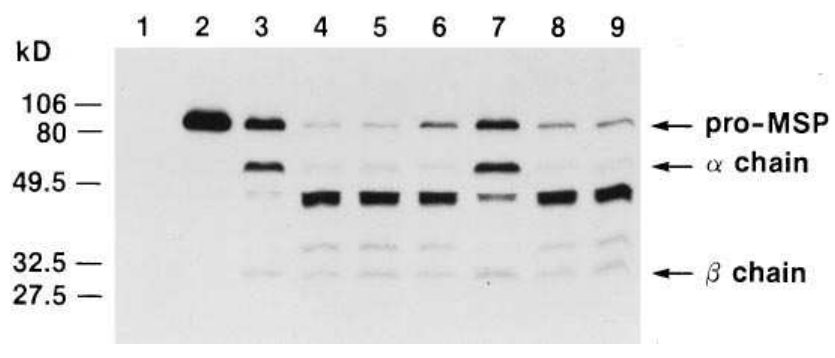

Figure 4. Effect of serine protease inhibitors on cleavage of pro-MSP by macrophages. Experimental conditions were as described for Fig. 3 , except for the addition of different protease inhibitors and a single incubation time of $3 \mathrm{~h}$. Labeled pro-MSP control without macrophages, immunoprecipitated with normal rabbit IgG (lane 1) and IgG anti-MSP (lane 2). Pro-MSP incubated with macrophages and $1 \mathrm{mM}$ AEBSF (lane 3), $2 \mu \mathrm{g} / \mathrm{ml}$ aprotinin (lane 4), $10 \mathrm{mM}$ EDTA (lane 5), $50 \mu \mathrm{g} / \mathrm{ml}$ leupeptin (lane 6), $50 \mu \mathrm{g} / \mathrm{ml}$ STI (lane 7), $1 \mathrm{mM}$ benzamidine (lane 8 ), and no inhibitor (lane 9). represented the $\alpha$ chain of mature MSP (Fig. 4, lanes 3 and 7). Thus, macrophages were capable of cleaving pro-MSP specifically and nonspecifically. AEBSF or STI inhibited nonspecific cleavage, allowing accumulation of the correctly processed two-chain form of MSP.

We reasoned that, if tissue macrophages were in contact with plasma-derived pro-MSP in vivo, plasma-derived protease inhibitors would also be present, and we therefore tested effects of human or mouse serum on cleavage of pro-MSP by resident peritoneal macrophages. Macrophages in serum-free medium cleaved pro-MSP completely; the absence of the mature MSP $\alpha$ chain shows that cleavage was nonspecific (Fig. 5, lane 2). Lane 3 shows that as little as a 1/1,000 dilution of mouse serum partially inhibited nonspecific cleavage, shown by the MSP $\alpha$ chain band as well as uncleaved pro-MSP. With increasing serum concentrations, cleavage of pro-MSP was increasingly inhibited, as shown by a more intense pro-MSP band and a less intense MSP $\alpha$ chain band (lanes 4-7).

To estimate the molecular mass of the serum inhibitor, we applied $0.2 \mathrm{ml}$ of human serum to an HPLC gel filtration column. Eluted fractions were assayed for their capacity to inhibit ${ }^{125}$ I-pro-MSP cleavage by murine resident peritoneal macrophages. A major peak of inhibitory activity was detected in fractions 43-47 (Fig. 6), as shown by increased intensity of proMSP and $\alpha$ chain bands and a decreased intensity in two of the fastest migrating cleavage product bands. This pattern is consistent with inhibition of nonspecific cleavage, with a resultant increase in the amount of mature MSP, as indicated by increased intensity of the $\alpha$ chain band. Based on its elution position, a rough approximation of the molecular mass of the inhibitor is $40 \mathrm{kD}$.

Effect of culture fluids from macrophages on cleavage of pro-MSP. We next assessed whether pro-MSP is processed by proteolytic enzymes secreted by macrophages or by enzymes bound to macrophages. Mouse peritoneal or exudate macrophages at a concentration of $10^{6}$ cells $/ \mathrm{ml}$ were cultured for

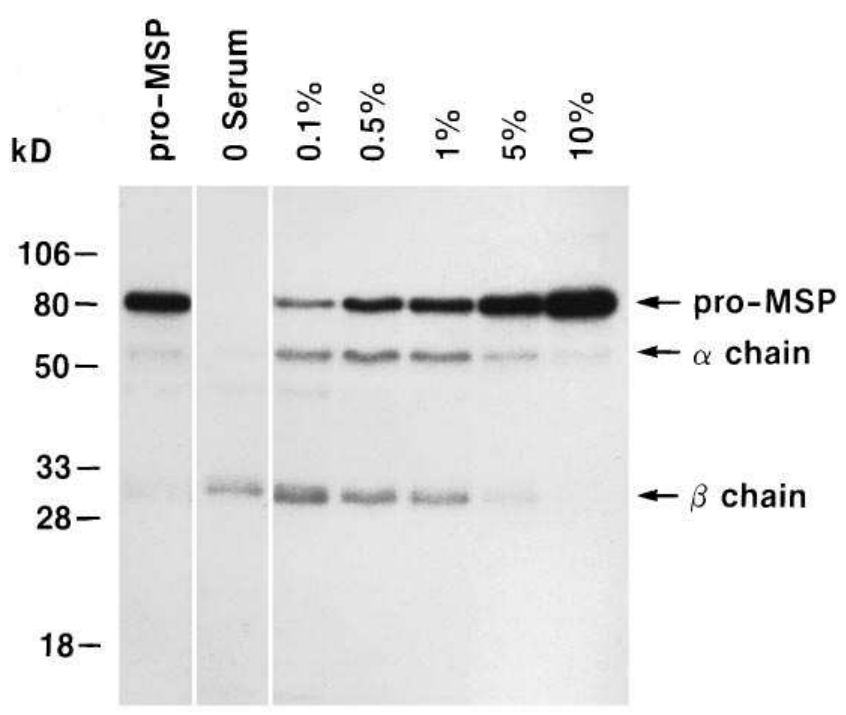

Figure 5. Inhibition by mouse serum of macrophage cleavage of proMSP. Experimental conditions were as described for Fig. 4, except that different concentrations of mouse serum (heated at $56^{\circ} \mathrm{C}$ for 30 $\mathrm{min}$ ) were added to the culture medium. Lane $1,{ }^{35} \mathrm{~S}$-pro-MSP control. Lanes 2-7, labeled MSP incubated for $3 \mathrm{~h}$ with macrophages in medium containing $0,0.1,0.5,1,5$, and $10 \%$ serum. 


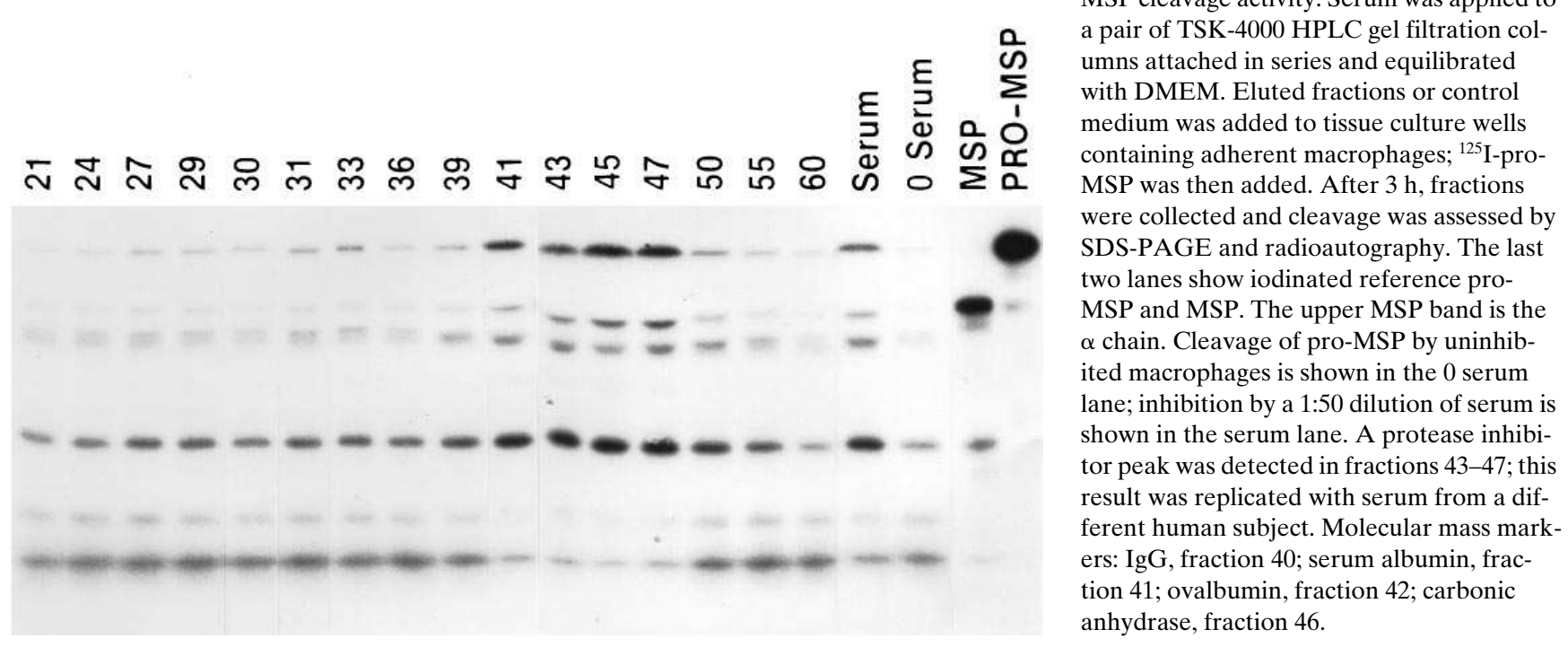

Figure 6. Assay of HPLC gel filtration fractions for serum inhibitor of macrophage proMSP cleavage activity. Serum was applied to a pair of TSK-4000 HPLC gel filtration columns attached in series and equilibrated with DMEM. Eluted fractions or control medium was added to tissue culture wells containing adherent macrophages; ${ }^{125}$ I-proMSP was then added. After $3 \mathrm{~h}$, fractions were collected and cleavage was assessed by band is the $\alpha$ chain. Cleavage of pro-MSP by uninhibited macrophages is shown in the 0 serum lane; inhibition by a 1:50 dilution of serum is shown in the serum lane. A protease inhibitor peak was detected in fractions $43-47$; this result was replicated with serum from a different human subject. Molecular mass marktion 41 ; ovalbumin, fraction 42 ; carbonic anhydrase, fraction 46 .

$24 \mathrm{~h}$ in serum-free medium with or without LPS. Culture fluids were collected and tested for their capacity to cleave ${ }^{35} \mathrm{~S}$-proMSP. Fig. 7 shows that culture fluids from resident or exudate macrophages, with or without LPS stimulation, did not cleave pro-MSP. Culture fluids from MSP-activated macrophages also did not cleave pro-MSP (data not shown).

We also asked if pro-MSP could be cleaved by mature MSP. In this study, $1 \mathrm{nM}$ MSP was mixed with $1.5 \mathrm{nM}$ ${ }^{35} \mathrm{~S}$-labeled pro-MSP and incubated $60 \mathrm{~min}$ at $37^{\circ} \mathrm{C}$. As shown in Fig. 7, lane 7, pro-MSP was not cleaved by mature MSP, indicating that autoactivation of pro-MSP by the mature cleavage product did not occur.

Cleavage of pro-MSP by macrophage cell membranes. The above results suggested that macrophage cleavage of pro-MSP and MSP was due to proteolytic enzymes associated with the cell membrane. Therefore, ${ }^{35} \mathrm{~S}$-labeled pro-MSP was incubated with cell membranes prepared from resident or exudate peritoneal macrophages. Fig. 8 shows that, after a 3-h incubation in the presence of STI or AEBSF, pro-MSP was partially cleaved to the mature $\alpha / \beta$ chain form of MSP by cell membranes from resident or exudate peritoneal macrophages (lanes 4, 5, 7, and

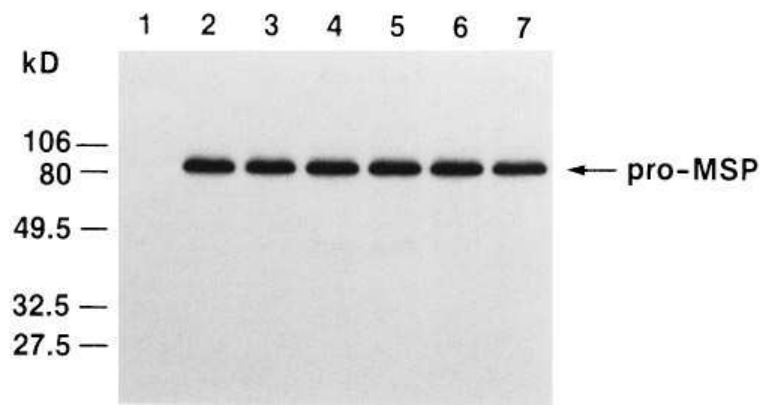

Figure 7. Effect of macrophage culture fluids on cleavage of proMSP. Culture fluids from resident or exudate macrophages stimulated with or without LPS were mixed with $1 \mathrm{nM}^{35} \mathrm{~S}$-pro-MSP at $37^{\circ} \mathrm{C}$ for $3 \mathrm{~h}$. Lane 1, normal rabbit IgG control; lane 2, pro-MSP control; lane 3, resident macrophages without LPS; lane 4, resident macrophages with LPS; lane 5, exudate macrophages without LPS; lane 6 , exudate macrophages with LPS; lane 7, pro-MSP with mature MSP.
$8)$. Without protease inhibitors, pro-MSP was cleaved nonspecifically (lanes 3 and 6). Thus, both nonspecific and specific pro-MSP cleavage enzymes are associated with macrophage cell membranes; nonspecific cleavage is inhibited by STI and AEBSF.

Biological activities of processed pro-MSP. We previously reported that incubation of resident peritoneal macrophages in tissue culture wells with mature MSP caused motile activity, as shown by ruffled membranes and elongated shapes (1). These changes occur within $1 \mathrm{~h}$ and can be seen by comparing Fig. 9, $A$ and $C$. Although pro-MSP had no effect (Fig. $9 E$ ), macrophages were stimulated by incubation with pro-MSP plus STI (Fig. $9 F$ ). Our interpretation of these findings is that proMSP alone had no effect because it was nonspecifically cleaved by target macrophages; when nonspecific cleavage was inhibited by STI, macrophages correctly processed pro-MSP to MSP and were stimulated by the product.

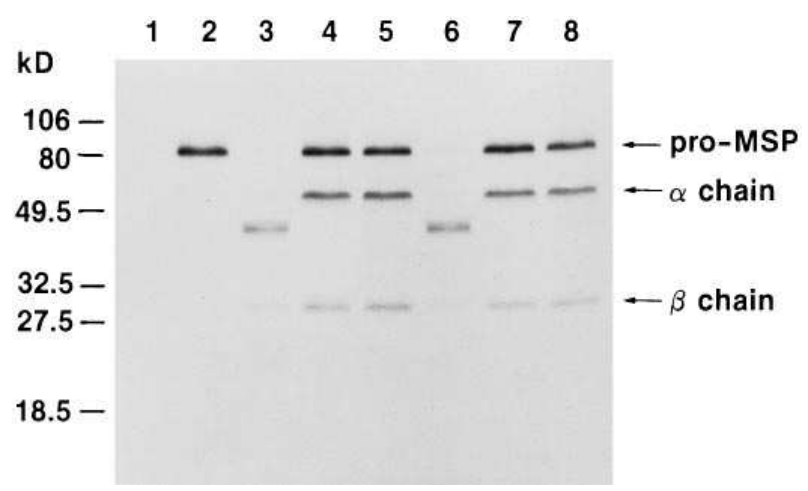

Figure 8 . Cleavage of pro-MSP by macrophage cell membranes. ${ }^{35} \mathrm{~S}$-proMSP was added at a final concentration of $1 \mathrm{nM}$ to $100 \mu \mathrm{g}$ of cell membranes from resident or exudate peritoneal macrophages with or without STI $(50 \mu \mathrm{g} / \mathrm{ml})$ or AEBSF $(1.5 \mathrm{mM})$ at $37^{\circ} \mathrm{C}$ for $3 \mathrm{~h}$. Lane 1 , normal rabbit IgG control; lane 2, pro-MSP control; lane 3, resident macrophage membranes without protease inhibitors; lane 4 , resident macrophage membranes with STI; lane 5, resident macrophage membranes with AEBSF; lane 6, exudate macrophage membranes without protease inhibitors; lane 7 , exudate macrophage membranes with STI; and lane 8 , exudate macrophage membranes with AEBSF. 

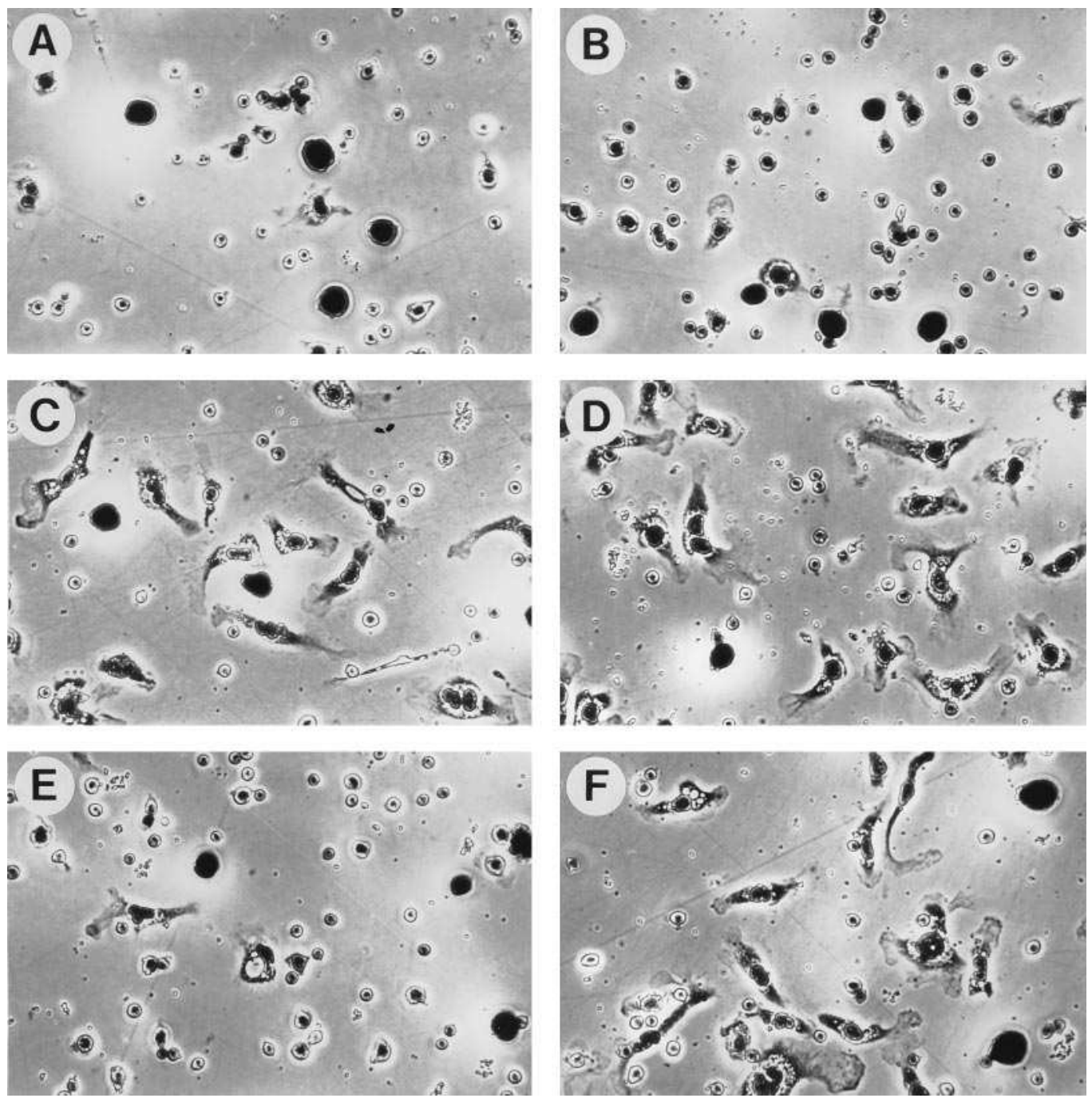

Figure 9. Induction of macrophage shape change by pro-MSP in the presence of STI. Culture conditions were as described for Fig. 3; incubation time was $3 \mathrm{~h}$. (A) Medium control; $(B)$ $100 \mu \mathrm{g} / \mathrm{ml} \mathrm{STI} ;(C) 1 \mathrm{nM}$ MSP; $(D) 1 \mathrm{nM}$ MSP + 100 $\mu \mathrm{g} / \mathrm{ml} \mathrm{STI} ;(E) 3 \mathrm{nM}$ proMSP; $(F) 3$ nM pro-MSP + $100 \mu \mathrm{g} / \mathrm{ml}$ STI.

Similar results were obtained when we tested the capacity of pro-MSP to stimulate resident macrophages to respond to a chemoattractant (endotoxin-activated mouse serum). Fig. 10 shows that pro-MSP alone did not induce cell migration to the chemoattractant. However, pro-MSP in the presence of STI induced macrophage migration, indicating that partial proteolytic cleavage of pro-MSP to MSP by macrophages occurred during the 90-min incubation period.

\section{Discussion}

The gene for MSP encodes a protein with a signal peptide sequence that is cleaved in conjuction with pro-MSP secretion (6). Among tissues surveyed by Northern blot, the liver has the most abundant MSP mRNA (6). Using a sandwich ELISA that does not distinguish between pro-MSP and MSP, we found nanomolar concentrations of this protein in normal human serum (18). We therefore postulated that, in analogy to other kringle proteins such as prothrombin and plasminogen, the liver constitutively secretes pro-MSP into the circulating blood. Fig. 1 shows that all the MSP detected in normal human serum is in the form of pro-MSP, the uncleaved $\alpha / \beta$ single protein chain. In view of our report that several pure enzymes of the coagulation cascade cleaved pro-MSP to the disulfide- linked $\alpha / \beta$ chain heterodimer, it was interesting to find that pro-MSP remained uncleaved when blood was shed, even without the addition of protease inhibitors. This suggests that the functional specificity of the coagulation cascade enzymes in vivo relates to affinity for substrate and transience of enzyme activity because of serum inhibitors.

A list of proteases with trypsin-type specificity that we have tested for pro-MSP convertase activity is shown in Table I. Except for the coagulation cascade enzymes and tissue kallikreins, these proteases either did not cleave or cleaved to inactive fragments. Since the coagulation system did not act as a pro-MSP convertase, the enzymes that could specifically cleave pro-MSP to biologically active MSP remained to be discovered.

We have now shown that resident murine peritoneal macrophages, one of the target cells for MSP, have enzymatic activities that proteolytically cleave pro-MSP. It is well known that mononuclear phagocytes produce many different proteolytic enzymes $(23,24)$, with a wide range of characteristics. They may be intracellular, bound on the external side of the plasma membrane, or secreted (25). Production may be restricted to a particular maturational stage of the cell (26), and it may be constitutive (26) or dependent on an inflammatory stimulus $(27,28)$. Macrophage proteases that cleave pro-MSP 


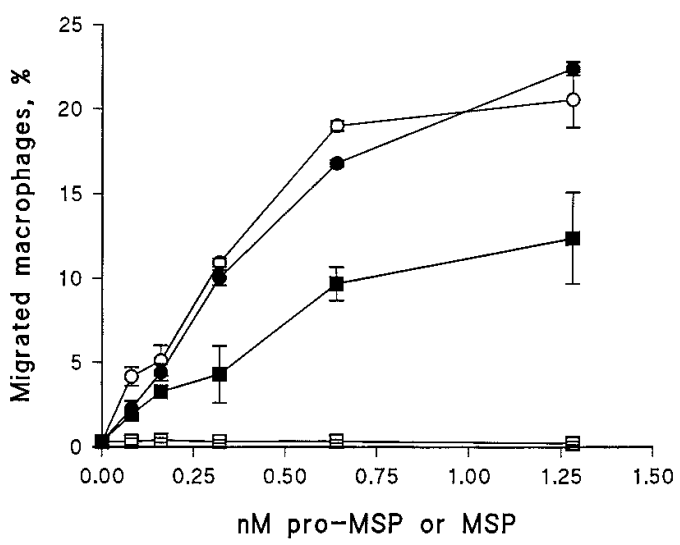

Figure 10. Stimulation of macrophage chemotactic responsiveness by pro-MSP in the presence of STI. Resident peritoneal macrophages in RPMI 1640 were incubated in a multiwell chemotaxis chamber for $3 \mathrm{~h}$ with reagents as indicated. Chemoattractant in bottom wells was a 1:100 dilution of endotoxin-activated mouse serum. (৩) $1 \mathrm{nM}$ MSP;

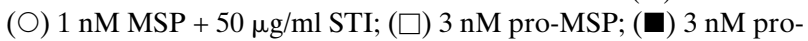
$\mathrm{MSP}+50 \mu \mathrm{g} / \mathrm{ml}$ STI.

are produced constitutively. They are membrane associated, and no activity was found in culture fluids of unstimulated or LPS-stimulated resident or exudate peritoneal macrophages. It appears that they are expressed relatively late in mononuclear phagocyte maturation, since human blood monocytes did not cleave pro-MSP. This was the expected result, inasmuch as plasma or serum contained pro-MSP without detectable MSP.

In contrast to many cytokines, which are synthesized and secreted as active proteins in response to inflammatory stimuli, typical members of the kringle protein family are secreted constitutively as biologically inactive zymogens. An additional measure of control is achieved if the convertase enzymes are localized on cell membranes instead of being widely distributed in extracellular fluid. For example, cleavage and activation of plasminogen by urokinase-type plasminogen activator (uPA) is greatly accelerated when uPA is cell bound (29). An example with a functional analogy to the specific and nonspe-

\section{Table I. Effects of Trypsin in Family Proteases on Pro-MSP}

\begin{tabular}{lr}
\hline Cleaves and activates & $n M^{*}$ \\
Clotting Factor Xlla $^{\ddagger}$ & 100 \\
Serum kallikrein & 50 \\
Clotting Factor Xla $^{\ddagger}$ & 6 \\
NGF- $\gamma^{\ddagger}$ & 1 \\
EGF-BP $^{\ddagger}$ & 1 \\
Cleaves to inactive fragments & \\
Plasmin & \\
Trypsin & \\
Does not cleave & \\
Thrombin & \\
Urokinase & \\
Porcine elastase & \\
Mast cell tryptase + heparin & \\
Factor VIIa + tissue factor &
\end{tabular}

* Concentration that cleaved $1.5 \mathrm{~nm}$ pro-MSP to MSP within $30 \mathrm{~min}$. ${ }^{\ddagger}$ Reference 32. ${ }^{\S}$ Reference $17 . ~ "$ Tested in current investigation; data not shown. cific pro-MSP cleavage activities is another pair of proteolytic enzymes that are constitutively expressed on resident murine peritoneal macrophage cell membranes. One of the enzymatic activities is a prothrombinase that cleaves and activates prothrombin, which is also in the kringle protein family (30). The other enzyme cleaves and inactivates thrombin (31); its activity is decreased in inflammatory macrophages. Thus, the enzyme pair may regulate coagulant activity at sites of inflammation.

The effects of STI on enzymatic cleavage of pro-MSP by macrophages are reflected in the bioassays shown in Figs. 9 and 10. Addition of pro-MSP to macrophages without protease inhibitors did not result in MSP biological activity but did when nonspecific cleavage was inhibited by including STI in the assay medium. In contrast to these data, which show that pure pro-MSP did not induce macrophage chemotactic responsiveness unless STI was added, human serum without added protease inhibitors had MSP activity in the same bioassay (1). Since our present work shows that human serum contains pro-MSP without MSP (Fig. 1), we postulated that the MSP activity of human serum is due to specific proteolytic cleavage of pro-MSP by the target macrophages, associated with inhibition of nonspecific enzyme activity by serum factors. Fig. 5 shows that serum can inhibit both specific and nonspecific cleavage of pro-MSP by macrophages and that there is a concentration range over which inhibition of nonspecific cleavage allows formation of mature MSP. Likewise, the HPLC gel filtration serum inhibitor peak allowed increased generation of mature MSP (as shown by the increased MSP $\alpha$ chain in Fig. 6).

Like many of its relatives in the coagulation and fibrinolytic systems, the cleavage site in pro-MSP that gives rise to $\alpha$ and $\beta$ chains is Arg, bonded to an aliphatic amino acid. This scissile bond is a target for serine proteases with trypsin-type specificity, the substrates for which have a Lys or Arg that occupies the active site of the enzyme. Like the coagulation enzymes and tissue kallikreins with pro-MSP convertase activity $(17,32)$, the macrophage enzyme that specifically cleaves proMSP is expected to be a trypsin-type serine protease. Although the nonspecific cleavage site in pro-MSP is unknown, it may well be a target for a trypsin-type serine protease, since nonspecific cleavage is inhibited by STI, the inhibitory center of which is Arg-isoleucine. Approximately $10 \%$, by weight, of all plasma protein is accounted for by protease inhibitors, which reflects their importance in regulation of plasma enzymatic cascades such as coagulation, fibrinolysis, and complement activation. Two superfamilies of plasma serine protease inhibitors have been described, the serpins and the Kunitztype protease inhibitors (33). Several members of these superfamilies failed to inhibit macrophage cleavage of pro-MSP (data not shown). These included $\alpha_{1}$-antitrypsin, C1-inhibitor, and anti-thrombin III in the serpin family, and pancreatic trypsin inhibitor (aprotinin) in the Kunitz-type inhibitor family. $\alpha_{2}$-Macroglobulin also did not inhibit. Another plasma inhibitor in the Kunitz family is inter- $\alpha$-trypsin inhibitor (I $\alpha \mathrm{TI})$, a multichain protein with a high molecular mass. In addition to the multichain $\mathrm{I} \alpha \mathrm{TI}$, the $30-\mathrm{kD}$ free light chain of $\mathrm{I} \alpha \mathrm{TI}(33,34)$ is also present in serum (synonyms are ITI-LC, bikunin, $\mathrm{HI}-30$ ). In view of its estimated molecular mass of $40 \mathrm{kD}$, it will be of interest to determine if the serum inhibitor of macrophage pro-MSP cleavage is I $\alpha$ TI light chain.

Expression of MSP biological activity in tissue sites must begin with proteolytic conversion of pro-MSP to MSP. Our 
data suggest that macrophage pro-MSP proteases and serum protease inhibitors are part of a pro-MSP/MSP control system. At sites of inflammation or injury with increased vascular permeability, pro-MSP may diffuse from the circulation into tissues where a macrophage convertase can cleave pro-MSP to biologically active MSP. MSP may then act on two of its target cells, macrophages and keratinocytes (35), which are important in wound healing. Precise control of MSP biological activity may be mediated by a macrophage-bound specific pro-MSP convertase that cleaves pro-MSP to mature MSP, by other macrophage-bound enzymes that degrade either pro-MSP or MSP, and by at least one serum inhibitor of macrophage proMSP cleavage. The final concentration of mature MSP at tissue sites will probably depend on a number of factors, including the maturational stage of the target cell (no pro-MSP convertase activity on monocytes) and local concentrations of serum-derived inhibitors of different cell membrane proteases.

\section{References}

1. Leonard, E.J., and A. Skeel. 1976. A serum protein that stimulates macrophage movement, chemotaxis and spreading. Exp. Cell Res. 102:434-438.

2. Leonard, E.J., and A.H. Skeel. 1978. Isolation of macrophage stimulating protein (MSP) from human serum. Exp. Cell Res. 114:117-126.

3. Skeel, A., and E.J. Leonard. 1994. Action and target cell specificity of human macrophage stimulating protein (MSP). J. Immunol. 152:4618-4623.

4. Skeel, A., T. Yoshimura, S. Showalter, S. Tanaka, E. Appella, and E. Leonard. 1991. Macrophage stimulating protein: purification, partial amino acid sequence, and cellular activity. J. Exp. Med. 173:1227-1234.

5. Wang, M.-H., G.W. Cox, T. Yoshimura, L.A. Sheffler, A. Skeel, and E.J. Leonard. 1994. Macrophage stimulating protein inhibits induction of nitric oxide production by endotoxin or cytokine-stimulated mouse macrophages. $J$. Biol. Chem. 269:14027-14031.

6. Yoshimura, T., N. Yuhki, M.-H. Wang, A. Skeel, and E.J. Leonard. 1993. Cloning, sequencing and expression of human macrophage stimulating protein (MSP) confirms MSP as a kringle protein, and locates the gene on chromosome 3. J. Biol. Chem. 268:15461-15468.

7. Sottrup-Jensen, L., M. Zajdel, H. Claeys, T.E. Petersen, and S. Magnusson. 1975. Amino-acid sequence of activation cleavage site in plasminogen: homology with "pro" part of prothrombin. Proc. Natl. Acad. Sci. USA. 72:25772581.

8. Park, C.H., and A. Tulinsky. 1986. Three-dimensional structure of the kringle sequence: structure of prothrombin fragment 1. Biochemistry. 25:39773982 .

9. Wun, T.C., L. Ossowski, and E. Reich. 1982. A proenzyme form of human urokinase. J. Biol. Chem. 257:7262-7268.

10. Nakamura, T., T. Nishizawa, M. Hagiya, T. Seki, M. Shimonishi, A. Sugimura, K. Tashiro, and S. Shimizu. 1989. Molecular cloning and expression of human hepatocyte growth factor. Nature (Lond.). 342:440-443.

11. Stoker, M., E. Gherardi, M. Perryman, and J. Gray. 1987. Scatter factor is a fibroblast-derived modulator of epithelial cell mobility. Nature (Lond.). 327:239-242.

12. Han, S., L.A. Stuart, and S.J.F. Degen. 1991. Characterization of the DNF15S2 locus on human chromosome 3: identification of a gene coding for four kringle domains with homology to hepatocyte growth factor. Biochemistry. 30:9768-9780.

13. Francis, C.W., and V.J. Marder. 1990. Mechanisms of fibrinolysis. In Hematology. W.J. Williams, E. Beutler, A.J. Erslev, and M.A. Lichtman, editors. McGraw-Hill, NY. 1313 pp.

14. Ronsin, C., F. Muscatelli, M.G. Mattei, and R. Breathnach. 1993. A novel putative receptor protein tyrosine kinase of the met family. Oncogene. 8:
1195-1202.

15. Wang, M.-H., C. Ronsin, M.-C. Gesnel, L. Coupey, A. Skeel, E.J. Leo nard, and R. Breathnach. 1994. Identification of the ron gene product as the receptor for the human macrophage stimulating protein. Science (Wash. DC). 266:117-119.

16. Gaudino, G., A. Follenzi, L. Naldini, C. Collesi, M. Santoro, K.A. Gallo, P.J. Godowski, and P.M. Comoglio. 1994. Ron is a heterodimeric tyrosine kinase receptor activated by the HGF homologue MSP. EMBO (Eur. Mol. Biol. Organ.) J. 13:3524-3532.

17. Wang, M.-H., T. Yoshimura, A. Skeel, and E.J. Leonard. 1994. Proteolytic conversion of single chain precursor macrophage-stimulating protein to a biologically active heterodimer by contact enzymes of the coagulation cascade. J. Biol. Chem. 269:3436-3440.

18. Wang, M.-H., A. Skeel, T. Yoshimura, T.D. Copeland, K. Sakaguchi, and E.J. Leonard. 1993. Antibodies to macrophage stimulating protein (MSP) specificity, epitope interactions, and immunoassay of MSP in human serum. $J$. Leukocyte Biol. 54:289-295.

19. Bolton, A.E., and W.M. Hunter. 1973. The labelling of proteins to high specific radioactivities by conjugation to a ${ }^{125} \mathrm{I}$-containing acylating agent. Biochem. J. 133:529-539.

20. Leonard, E.J., and A. Skeel. 1985. Disposable microliter immunoabsorbent columns: construction and operation. J. Immunol. Methods. 82:341-348.

21. Crann, S.A., M.Y. Huang, J.D. McLaren, and J. Schacht. 1992. Formation of a toxic metabolite from gentamicin by a hepatic cytosolic fraction. Biochem. Pharmacol. 43:1835-1839.

22. Leonard, E.J., and A. Skeel. 1981. Effects of cell concentration on chemotactic responsiveness of mouse resident peritoneal macrophages. J. Reticuloendothel. Soc. 30:271-282.

23. Shi, G.P., J.S. Munger, J.P. Meara, D.H. Rich, and H.A. Chapman. 1992. Molecular cloning and expression of human alveolar macrophage cathepsin S, an elastinolytic cysteine protease. J. Biol. Chem. 267:7258-7262.

24. Nathan, C.F. 1987. Secretory products of macrophages. J. Clin. Invest. 79:319-326.

25. Werb, Z., D.F. Bainton, and P.A. Jones. 1980. Degradation of connective tissue matrices by macrophages. III. Morphological and biochemical studies on extracellular, pericellular, and intracellular events in matrix proteolysis by macrophages in culture. J. Exp. Med. 152:1537-1553.

26. Welgus, H.G., E.J. Campbell, J.D. Cury, A.Z. Eisen, R.M. Senior, S.M. Wilhelm, and G.I. Goldberg. 1990. Neutral metalloproteinases produced by human mononuclear phagocytes. Enzyme profile, regulation, and expression during cellular development. J. Clin. Invest. 86:1496-1502.

27. Adams, D.O., and T.A. Hamilton. 1984. The cell biology of macrophage activation. Annu. Rev. Immunol. 2:283-318.

28. Werfel, T., G. Sonntag, M.H. Weber, and O. Gotze. 1991. Rapid increases in the membrane expression of neutral endopeptidase (CD10), aminopeptidase $\mathrm{N}$ (CD13), tyrosine phosphatase (CD45), and Fc gamma-RII (CD16) upon stimulation of human peripheral leukocytes with human C5a. J. Immunol. 147:3909-3914.

29. Ellis, V., and K. Dan. 1991. Plasminogen activation by receptor-bound urokinase. Semin. Thromb. Hemostasis. 17:194-200.

30. Lindahl, U., G. Pejler, J. Bogwald, and R. Seljelid. 1989. A prothrombinase complex of mouse peritoneal macrophages. Arch. Biochem. Biophys. 273: 180-188.

31. Pejler, G., and R. Seljelid. 1992. Inactivation of thrombin by murine peritoneal macrophages. J. Biol. Chem. 267:3136-3142.

32. Wang, M.-H., S.L. Gonias, A. Skeel, B.B. Wolf, T. Yoshimura, and E.J. Leonard. 1994. Proteolytic activation of single-chain precursor macrophage stimulating protein by nerve growth factor- $\gamma$ and epidermal growth factor binding protein, members of the kallikrein family. J. Biol. Chem. 269:13806-13810.

33. Salier, J.P. 1990. Inter-alpha-trypsin inhibitor: emergence of a family within the Kunitz-type protease inhibitor superfamily. Trends Biochem. Sci. 15 435-439.

34. Thogersen, I.B., and J.J. Enghild. 1995. Biosynthesis of bikunin proteins in the human carcinoma cell line HepG2 and in primary human hepatocytes. Polypeptide assembly by glycosaminoglycan. J. Biol. Chem. 270:18700-18709.

35. Wang, M.-H., and E.J. Leonard. 1995. Macrophage stimulating protein: from macrophage chemotaxis to keratinocyte mitogenesis. J. NIH Res. 7:47. 